\section{Power spectral analysis of heart rate and blood pressure variability in lumbar epidural anaesthesia}

Masayuki Arakawa MD, Fumio Goto MD PhD
The purpose of this study was to evaluate autonomic nervous system activity during high and low lumbar epidural anaesthesia. Ten patients undergoing lower limb surgery with lumbar epidural anaesthesia (low epidural anaesthesia group; mean upper dermal block level, $T_{10.7 \pm 1.1}$, and ten patients undergoing either abdominal total hysterectomy or ingunial hernia under lumbar epidural anaestehsia (high epidural anaesthesia group; mean upper dermal block level, $T_{5.1 \pm 1.0}$. Ten healthy volunteers were used as the control group. The autonomic nervous system activity was measured by heart rate and blood pressure variability with power spectral analysis. For the analysis of heart rate variability, frequency components were divided into two factors, a low frequency component RR (LFCRR: $0.03 \mathrm{~Hz}-0.15$ $\mathrm{Hz}$ ) that mediated sympathetic and parasympathetic activity and a high frequency component RR (HFCRR: $0.15 \mathrm{~Hz}-0.4$ $\mathrm{Hz}$ ) that mediated parasympathetic activity. In the analysis of blood pressure variability, the frequency components were also divided into two factors; a low frequency component of systolic blood pressure and diastolic blood pressure (LFCSBP and LFCDBP: $0.03 \mathrm{~Hz}-0.15 \mathrm{~Hz}$ ) that was mediated by peripheral sympathetic vasomotor activity and a higher frequency component of systolic blood pressure and diastolic blood pressure (HFCSBP and HFCDBP: $0.15 \mathrm{~Hz}-0.4 \mathrm{~Hz}$ ) that was mediated by a mechanical consequence of respiration. There were no changes in heart rate variability during epidural anaesthesia. However, LFCSBP and LFCDBP decreased in high epidural anaesthesia $(P<0.01)$. On the contrary, LFCSBP increased in low epidural anaesthesia $(P<0.01)$. We conclude that peripheral sympathetic vasomotor activity was activated in low

\section{Key words}

ANAESTHETIC TECHNIQUES: epidural; MONITORING: blood pressure, ECG.

From the Department of Anesthesiology, Kitasato University School of Medicine, Sagamihara, Kanagawa 228, Japan.

Address correspondence to: Dr. Masayuki Arakawa, Department of Anesthesiology, Kitasato University School of Medicine, Kitasato 1-15-1, Sagamihara, Kanagawa 228, Japan. Accepted for publication 20th April, 1994. epidural anaesthesia and suppressed in high epidural anaesthesia.

L'objectif de cette étude consistait à évaluer l'activité au système nerveux autonome pendant l'anesthésie épidurale haute et basse. Faisaient partie de létude: dix sujets opérés au membre inférieur sous anesthésie épidurale lombaire (groupe de l'épidurale basse; niveau métamérique cutané moyen bloqué, $T_{10,7 \pm 1,1}$ et dix sujets opérés soit pour hystérectomie abdominale totale ou cure de hernie inguinale sous épidurale lombaire (groupe de l'épidurale haute; niveau métamérique cutané moyen bloqué, $T_{5 \pm 1,0}$. Dix volontaires bien portants constituaient le groupe de contrôle. L'activité nerveuse autonome a été mesurée par la variabilité de la fréquence cardiaque et de la pression artérielle par analyse spectrale de puissance. Pour l'analyse de la variabilité de la fréquence cardiaque, les composantes des fréquences ont été divisées en deux facteurs: une composante $R R$ de basse fréquence ( $L F C R R: 0,03 \mathrm{~Hz}-0,15 \mathrm{~Hz}$ ) médiatrice de l'activité sympathique et parasympathique, et une composante de haute fréquence $R R$ (HFCRR: 0,15 Hz-0,4 Hz) médiatrice de l'activité parasympathique. Pour l'analyse de la variabilité de la pression artérielle, les composantes des fréquences ont aussi été divisées en deux facteurs: une composante de basse fréquence de pressions artérielles systolique et diastolique (LFCSBP et LFCDBP) et une composante de haute fréquence des pressions systolique et diastolique (HFCSBP et HFCDBP: $0,15 \mathrm{~Hz}-0,4 \mathrm{~Hz}$ ) médiatrice d'un effet mécanique de la respiration. La variabilité de la fréquence cardiaque n'a pas changé pendant l'anesthésie épidurale. Cependant, les LFCSBP et $L F C D B P$ ont diminué pendant l'épidurale haute $(P<0,01)$. Nous concluons que l'activité vasomotrice sympathique périphérique était activée pendant l'épidurale basse et supprimée pendant l'épidurale haute.

Sympathetic and parasympathetic activity vary during epidural anaesthesia. The variance of each activity is different due to the anaesthetized area. Lumbar epidural anaesthesia suppresses sympathetic activity in the anaesthetized area ${ }^{1-3}$ and activates sympathetic activity in an 
unanaesthetized area. ${ }^{4}$ Power spectral analysis of heart rate and blood pressure variability has been used to analyse the frequency distribution of beat-to-beat fluctuations in heart rate and blood pressure and to determine the differences between sympathetic and parasympathetic interaction. ${ }^{5}$ Spectral analysis involves the separation of the signal into a sum of sine waves as a function of frequency. In humans, two major spectral components of heart rate variability using power spectral analysis have been identified, a low frequency component (LFCRR) and a high frequency component (HFCRR). ${ }^{6}$ The LFCRR is mediated by parasympathetic and sympathetic activity, whereas the HFCRR corresponds to a respiration-linked component and reflects only parasympathetic activity. The power spectral density of blood pressure variability also consists of two major components: ${ }^{5,7-9}$ low frequency components of systolic (LFCSBP) and diastolic blood pressure (LFCDBP), and high frequency components of systolic (HFCSBP) and diastolic blood pressure (HFCDBP). The low frequency component indicates sympathetic activity and reflects peripheral sympathetic vasomotor activity. ${ }^{9,10}$ The high frequency component of blood pressure is mediated by a mechanical consequence of respiration, which may act directly on intrathoracic vessels or indirectly through changes in stroke volume and heart period. ${ }^{9}$

In this study we compared the changes in heart rate and blood pressure variability when the level of block analgesia was below $\mathrm{T}_{5}$ (high epidural anaesthesia group) or at $T_{10}$ (low epidural anaesthesia group). The interaction between sympathetic and parasympathetic activity, using power spectral analysis based on the Fast Fourier transform (FFT), in the area of lumbar epidural anaesthesia was studied.

\section{Methods}

After Institutional Ethics Committee approval and informed consent was obtained, ten ASA class I patients undergoing lower limb surgery with lumbar epidural anaesthesia (low epidural anaesthesia group) and ten ASA class I patients undergoing either abdominal total hysterectomy or inguinal hernia under lumbar epidural anaesthesia (high epidural anaesthesia group) were studied. In both groups there were no cardiac or respiratory complications and none was taking regular medication. Premedication with $10 \mathrm{mg}$ diazepam (po) was given to all patients two hours before the induction of anaesthesia. Ten healthy adult volunteers, who did not receive premedication or epidural anaesthesia, were included as a control group.

In the operating room, electrocardiogram (ECG) (BP306, Nihon Colin, Komaki, Japan) and the tonometric blood pressure of the radial artery were monitored con- tinuously (CBM-7000, Nihon Colin, Komaki, Japan). The arterial tonometory is a noninvasive technique for continuous monitoring of arterial blood pressure and can provide accurate, reliable, and real time monitoring of blood pressure. ${ }^{11}$ A tonometric sensor was attached to the extended wrist. The radial artery was used because of its large diameter and easy accessibility. A cuff was wrapped around the upper arm and the tonometric blood pressure was calibrated against the oscillometric blood pressure of the brachial artery. An intravenous cannula was inserted into the antecubital vein and Ringer's lactate solution was administered at a rate of 10-15 $\mathrm{ml} \cdot \mathrm{kg}^{-1} \cdot \mathrm{hr}^{-1}$.

In the low epidural anaesthesia group, an epidural catheter was inserted into the epidural space at the $\mathrm{L}_{3}-\mathrm{L}_{4}$ or $\mathrm{L}_{4}-\mathrm{L}_{5}$ level. In the high epidural anaesthesia group, the catheter was inserted into the $\mathrm{L}_{1}-\mathrm{L}_{2}$ or $\mathrm{L}_{2}-\mathrm{L}_{3}$ level. Following fixation of the catheter, $14 \mathrm{ml}$ mepivacaine (2\%) was injected in the low epidural anaesthesia group, and $16 \mathrm{ml}$ mepivacaine (2\%) was injected in the high epidural anaesthesia group. The dermal level of epidural anaesthesia was determined by the loss of cold sensation. Heart rate and blood pressure variability were measured before the epidural puncture and $20 \mathrm{~min}$ after the injection of mepivacaine into the epidural space. No vasopressor drugs were administered throughout the study. Respiration was spontaneous during this study.

In the control group, heart rate and blood pressure variability was determined twice at 20 -min intervals.

\section{Analysis of heart rate and blood pressure variability}

On-line analysis of RR intervals and blood pressure was performed using a microcomputer (PC9801VM, NEC, Tokyo, Japan). The occurrence of RR waves was detected from $\mathrm{R}$ wave of the ECG and blood pressure was measured from tonometric blood pressure waveforms (Figure 1 A, B, D, E). These data were stored on a floppy disk. Off-line spectral analysis was performed on $128 \mathrm{sec}$ segments of RR intervals in ECG and systolic and diastolic blood pressure data. However, the raw RR interval and blood pressure data were not equidistantly spaced when they were measured every beat to beat. The raw RR intervals and blood pressure data were converted to equidistant spacing for the spectral analysis. From the instantaneous heart rate and blood pressure data for 128 sec, RR intervals and blood pressure segments were converted to equidistant spacing. These segments were sampled at a rate of $8 \mathrm{~Hz}$ to produce a 1024 point time series of the instantaneous heart rate and blood pressure. These heart rate and blood pressure data were used, following low pass filtration to remove high frequency components. The power spectrum of each 1024 point time series was computed using the FFT programme (Auto- 
A

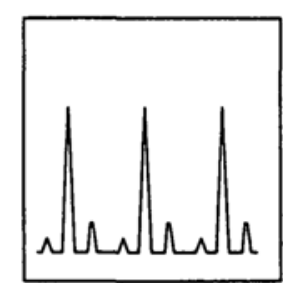

D

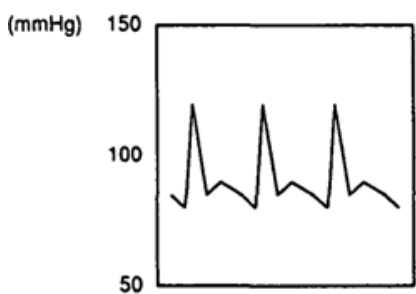

B

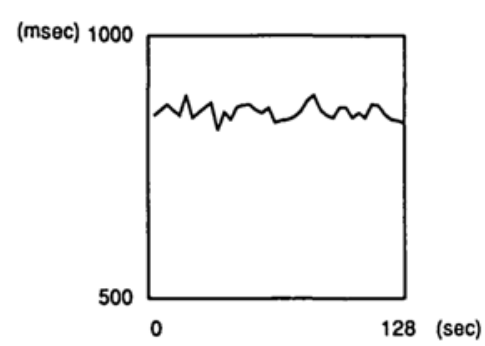

E

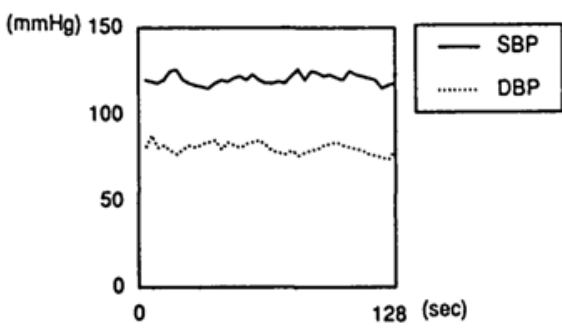

C

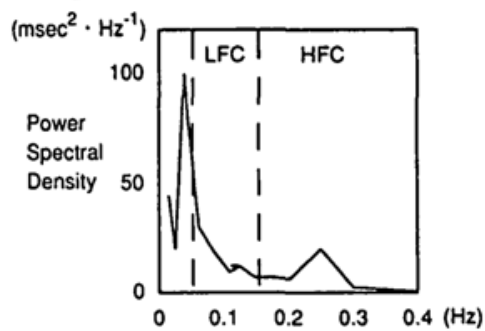

$F$

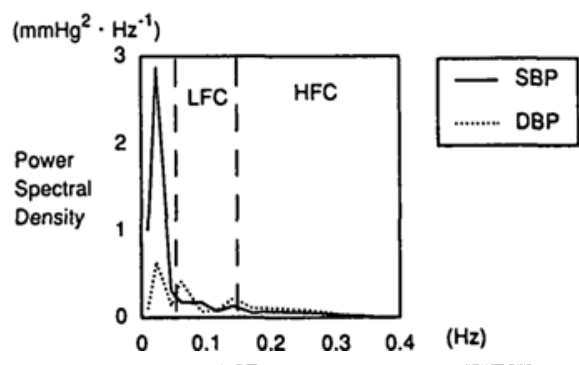

FIGURE I Schematic outline of spectral analysis of heart rate and blood pressure variability. A: ECG wave. B: RR interval trendgram. C: A power spectrum of heart rate variability from $128 \mathrm{sec}$ data using Fast Fourier transform. D: beat to beat blood pressure waveforms from arterial tonometry. E: blood pressure trendgram. F: a power spectrum of blood pressure variability from $128 \mathrm{sec}$ using fast Fourier transform. LFC: low frequency component. HFC: high frequency component.

TABLE I Patient demographic data, fluid administration, and the level of anaesthesia

\begin{tabular}{lccc}
\hline & $\begin{array}{c}\text { Control group } \\
n=10\end{array}$ & $\begin{array}{l}\text { Low epidural anaesthesia group } \\
n=10\end{array}$ & $\begin{array}{l}\text { High epidural anaesthesia group } \\
n=10\end{array}$ \\
\hline Age $(\mathrm{yr})$ & $34.1 \pm 9.5$ & $34.8 \pm 12.6$ & $39.9 \pm 8.2$ \\
Height $(\mathrm{cm})$ & $161.6 \pm 6.3$ & $165.4 \pm 9.4$ & $159.2 \pm 6.0$ \\
Weight $(\mathrm{kg})$ & $59.7 \pm 6.6$ & $61.8 \pm 7.3$ & $56.9 \pm 6.3$ \\
Fluid administration $\left(\mathrm{ml} \cdot \mathrm{kg}^{-1} \cdot \mathrm{hr}^{-1}\right.$ & - & $10.4 \pm 2.5$ & $15.0 \pm 4.0^{*}$ \\
Cephalad level & - & $\mathrm{T}_{10.7} \pm 1.1\left(\mathrm{~T}_{10}-\mathrm{L}_{1}\right)$ & $\mathrm{T}_{5.1} \pm 1.0^{*}\left(\mathrm{~T}_{4-6}\right)$ \\
Caudal level & - & $\mathrm{S}_{1.1} \pm\left(\mathrm{L}_{4}-\mathrm{S}_{4}\right)$ & $\mathrm{S}_{1.4} \pm 1.1\left(\mathrm{~L}_{4}-\mathrm{S}_{4}\right)$ \\
Block segments & - & $7.3 \pm 1.8$ & $12.5 \pm 1.2^{*}$ \\
\hline
\end{tabular}

Values are mean $\pm S D$. Numbers in parentheses represent the range.

${ }^{*} P<0.01$; compared with low epidural anaesthesia group.

nomic Nervous System Analysis, Nihon Colin, Komaki, Japan) (Figure 1 C, F).

Heart rate spectral analysis was quantified by determining the areas of the spectrum in two component widths (LFCRR; 0.03-0.15 Hz, HFCRR: 0.15-0.4 Hz). Total power was determined as the sum of each component. The LFCRR/HFCRR ratio, an index of sympathetic and parasympathetic interaction, ${ }^{5}$ was also determined. The systolic and diastolic blood pressure spectra were quantified by determining the areas of the spectrum in each two component width (systolic blood pressure: LFCsBP; $0.03-0.15 \mathrm{~Hz}$, HFCsBP; $0.15-0.4 \mathrm{~Hz}$, diastolic blood pressure: LFCDBP; $0.03-0.15 \mathrm{~Hz}$, HFCDBP; $0.15-0.4 \mathrm{~Hz}$ ).

Data are presented as mean \pm SD. Student's unpaired $t$ test was used to compare the low and high epidural anaesthesia groups. One-way analysis of variance (ANOVA) was used for repeated measures and multiple $t$ tests with Bonferroni correction were used for comparisons among the three groups. A paired $t$ test was used for differences within groups. A value of $P<0.05$ was considered statistically significant.

\section{Results}

There were no differences in age, body weight, and height or of blood pressure and heart rate among the three groups (Table I). There were differences in sensory block levels or fluid administration volume between the low epidural anaesthesia group and the high epidural anaesthesia group (Table I, Figure 2). 


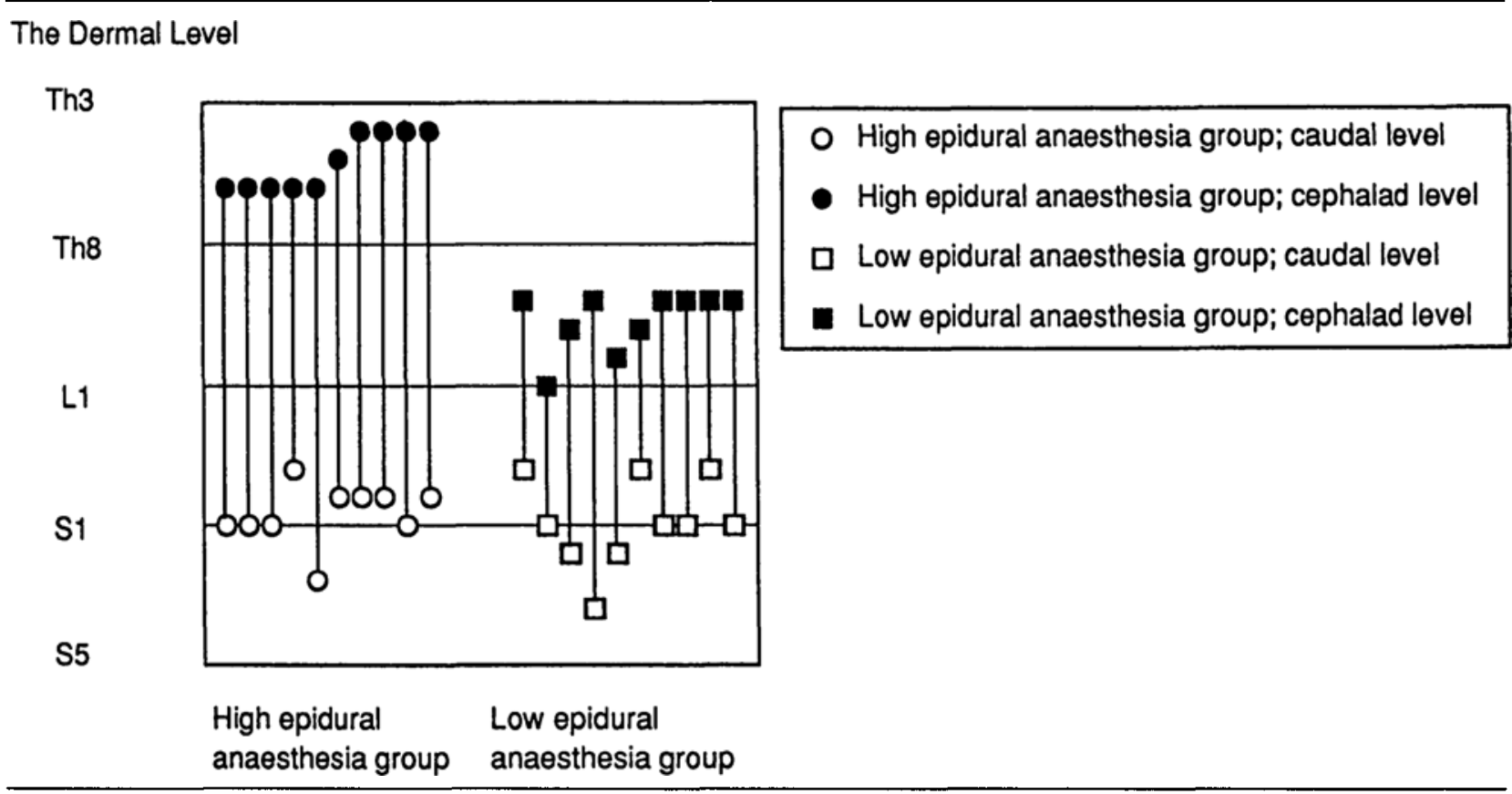

FIGURE 2 The dermatome area during epidural anaesthesia between the two groups. Mean upper sensory block level was $\mathrm{T}_{5.1}$ in the high epidural anaesthesia group and $\mathrm{T}_{10.7}$ in the low epidural anaesthesia group $(P<0.01)$. Horizonal bars represent the dermatome level.

TABLE II Heart rate variability

\begin{tabular}{|c|c|c|c|c|c|c|}
\hline & \multicolumn{2}{|c|}{ Control group $(n=10)$} & \multicolumn{2}{|c|}{ Low epidural anaesthesia group $(n=10)$} & \multicolumn{2}{|c|}{ High epidural anaesthesia group $(n=10)$} \\
\hline & $0 \min$ & Afier $20 \mathrm{~min}$ & Before anaesthesia & During anaesthesia & Before anaesthesia & During anaesthesia \\
\hline Heart rate $(\mathrm{bpm})$ & $68.5 \pm 6.3$ & $67.2 \pm 6.3$ & $68.5 \pm 9.5$ & $70.9 \pm 12.0$ & $73.6 \pm 12.0$ & $67.9 \pm 12.3$ \\
\hline $\mathrm{RR}$ interval (msec) & $885.4 \pm 80.6$ & $901.4 \pm 82.2$ & $893.7 \pm 122.9$ & $868.5 \pm 135.9$ & $842.9 \pm 146.6$ & $887.8 \pm 152.9$ \\
\hline $\begin{array}{l}\text { Respiratory rate } \\
\text { (breath } \cdot \min ^{-1} \text { ) }\end{array}$ & $17.1 \pm 2.0$ & $17.5 \pm 2.2$ & $18.0 \pm 2.9$ & $17.0 \pm 2.5$ & $18.9 \pm 3.6$ & $17.8 \pm 2.9$ \\
\hline \multicolumn{7}{|l|}{ LFCRR } \\
\hline Peak frequency $(\mathrm{Hz})$ & $0.058 \pm 0.019$ & $0.060 \pm 0.022$ & $0.062 \pm 0.030$ & $0.045 \pm 0.014$ & $0.061 \pm 0.031$ & $0.054 \pm 0.015$ \\
\hline Power $\left(\mathrm{msec}^{2}\right)$ & $302.4 \pm 145.9$ & $319.1 \pm 165.9$ & $283.3 \pm 158.6$ & $261.8 \pm 155.7$ & $341.5 \pm 249.0$ & $354.0 \pm 537.8$ \\
\hline \multicolumn{7}{|l|}{ HFCRR } \\
\hline Peak frequency $(\mathrm{Hz})$ & $0.273 \pm 0.088$ & $0.254 \pm 0.073$ & $0.25 \pm 0.044$ & $0.22 \pm 0.034$ & $0.252 \pm 0.039$ & $0.262 \pm 0.061$ \\
\hline Power $\left(\mathrm{msec}^{2}\right)$ & $102.2 \pm 105.2$ & $136.0 \pm 124.5$ & $125.0 \pm 66.9$ & $76.0 \pm 39.5$ & $79.7 \pm 57.5$ & $142.9 \pm 129.2$ \\
\hline LFCRR/HFCRR ratio & $3.6 \pm 1.8$ & $3.5 \pm 2.2$ & $2.9 \pm 2.2$ & $4.6 \pm 3.1$ & $4.5 \pm 1.4$ & $3.1 \pm 2.2$ \\
\hline
\end{tabular}

Values are mean $\pm \mathrm{SD}$.

A comparison of the spectral components of heart rate variability and respiratory rate during the resting preoperative period with that at $20 \mathrm{~min}$ after the administration of a local anaesthetic into the epidural space is shown in Table II. A comparison of the spectral components of systolic blood pressure variability before anaesthesia with that at $20 \mathrm{~min}$ after injection of a local anaesthetic into the epidural space is shown in Table III. In the low epidural anaesthesia group, the power of LFCsBP in- creased during epidural anaesthesia $(P<0.05)$ and was higher than in the control group $(P<0.01)$. On the other hand, in the high epidural anaesthesia group, the power of LFCSBP decreased during epidural anaesthesia $(P<0.01)$ and was lower than in the control group $(P<0.01)$. Table IV shows the comparison of spectral components of diastolic blood pressure variability. In the high epidural anaesthesia group, the power of LFCDBP significantly decreased during epidural anaesthesia $(P<$ 
TABLE III Systolic blood pressure variables

\begin{tabular}{|c|c|c|c|c|c|c|}
\hline & \multicolumn{2}{|c|}{ Control group $(n=10)$} & \multicolumn{2}{|c|}{ Low epidural anaesthesia group $(n=10)$} & \multicolumn{2}{|c|}{ High epidural anaesthesia group $(n=10$} \\
\hline & $0 \min$ & Afier $20 \mathrm{~min}$ & Before anaesthesia & During anaesthesia & Before anaesthesia & During anaesthesia \\
\hline \multicolumn{3}{|l|}{ Systolic blood pressure } & $123.8 \pm 8.2$ & $125.0 \pm 11.6$ & $126.0 \pm 13.5$ & $122.1 \pm 12.6$ \\
\hline \multicolumn{7}{|l|}{ LFCSBP } \\
\hline Peak frequency $(\mathrm{Hz})$ & $0.034 \pm 0.022$ & $0.031 \pm 0.015$ & $0.052 \pm 0.023$ & $0.043 \pm 0.016$ & $0.054 \pm 0.013$ & $0.053 \pm 0.030$ \\
\hline Power $\left(\mathrm{mmHg}^{2}\right)$ & $2.8 \pm 1.3$ & $3.1 \pm 1.0$ & $2.6 \pm 1.4$ & $4.9 \pm 3.4^{*} \dagger$ & $2.5 \pm 1.0$ & $0.80 \pm 0.44^{*} \ddagger$ \\
\hline \multicolumn{7}{|l|}{ HFCSBP } \\
\hline Peak frequency $(\mathrm{Hz})$ & $0.24 \pm 0.079$ & $0.28 \pm 0.063$ & $0.25 \pm 0.034$ & $0.24 \pm 0.028$ & $0.24 \pm 0.047$ & $0.23 \pm 0.060$ \\
\hline Power $\left(\mathrm{mmHg}^{2}\right)$ & $0.58 \pm 0.63$ & $0.43 \pm 0.30$ & $0.43 \pm 0.63$ & $0.42 \pm 0.38$ & $0.344 \pm 0.23$ & $0.376 \pm 0.31$ \\
\hline
\end{tabular}

Values are mean $\pm \mathrm{SD}$.

$* P<0.01$; compared with after $20 \mathrm{~min}$ in control group.

$\dagger P<0.05, \ddagger P<0.01$; compared with before anaesthesia in each group.

TABLE IV Diastolic blood pressure variabilities

\begin{tabular}{|c|c|c|c|c|c|c|}
\hline & \multicolumn{2}{|c|}{ Control group $(n=10)$} & \multicolumn{2}{|c|}{ Low epidural anaesthesia group $(n=10)$} & \multicolumn{2}{|c|}{ High epidural anaesthesia group $(n=10)$} \\
\hline & $0 \min$ & After $20 \mathrm{~min}$ & Before anaesthesia & During anaesthesia & Before anaesthesia & During anaesthesia \\
\hline $\begin{array}{l}\text { Diastolic blood pressure } \\
(\mathrm{mmHg})\end{array}$ & $70.5 \pm 7.9$ & $70.5 \pm 10.4$ & $72.9 \pm 9.4$ & $71.8 \pm 11.3$ & $67.7 \pm 9.4$ & $69.5 \pm 9.1$ \\
\hline $\begin{array}{l}\text { LFCDBP } \\
\text { Peak frequency }(\mathrm{Hz}) \\
\text { Power }\left(\mathrm{mmHg}^{2}\right)\end{array}$ & $\begin{array}{c}0.050 \pm 0.015 \\
2.0 \pm 0.91\end{array}$ & $\begin{array}{c}0.043 \pm 0.010 \\
3.3 \pm 1.5\end{array}$ & $\begin{array}{c}0.061 \pm 0.030 \\
1.3 \pm 0.82\end{array}$ & $\begin{array}{c}0.051 \pm 0.016 \\
1.8 \pm 0.85\end{array}$ & $\begin{array}{c}0.049 \pm 0.013 \\
2.1 \pm 0.88\end{array}$ & $\begin{array}{r}0.056 \pm 0.0031 \\
0.86 \pm 0.66 * \dagger\end{array}$ \\
\hline $\begin{array}{l}\operatorname{HFCDBP}\left(\mathrm{Hz}_{2}\right) \\
\text { Power }\left(\mathrm{mmHg}^{2}\right)\end{array}$ & $\begin{array}{l}0.23 \pm 0.075 \\
0.28 \pm 0.16\end{array}$ & $\begin{array}{l}0.26 \pm 0.079 \\
0.65 \pm 0.37\end{array}$ & $\begin{array}{l}0.26 \pm 0.053 \\
0.18 \pm 0.66\end{array}$ & $\begin{array}{l}0.22 \pm 0.037 \\
0.29 \pm 0.19\end{array}$ & $\begin{array}{l}0.25 \pm 0.066 \\
0.41 \pm 0.63\end{array}$ & $\begin{array}{l}0.23 \pm 0.044 \\
0.39 \pm 0.53\end{array}$ \\
\hline
\end{tabular}

Values are mean $\pm \mathrm{SD}$.

$* P<0.01$; compared with after $20 \mathrm{~min}$ in control group.

$\dagger P<0.05$; compared with before anaesthesia in high epidural anaesthesia group.

$0.05)$ and was lower than in the control group ( $P<$ 0.01 ).

The power spectrum of blood pressure variability during low epidural anaesthesia is shown in Figure 3. The LFCSBP increased due to low epidural anaesthesia. The power spectrum of blood pressure variability during high lumbar epidural anaesthesia is shown in Figure 4: LFCSBP decreased due to high epidural anaesthesia.

\section{Discussion}

There was a change in LFCsBP after epidural anaesthesia. In the low epidural anaesthesia group, LFCsBP increased. On the contrary, in the high epidural anaesthesia group, LFCSBP and LFCDBP decreased. The LFCSBP corresponds to Mayer waves. ${ }^{9,12}$ Although the origin of Mayer waves is not completely clear. However, it has been reported that they appear as a resonance phenomenon due to the delay in the sympathetic control loop of the baroreflex. ${ }^{12}$ The LFCSBP is decreased after administration of phentolamine in humans ${ }^{7}$ and after prazosin treatment in rats. ${ }^{8}$ This suggests that the $\alpha$-adrenergic system plays a dominant role in vasomotor activity. ${ }^{7,8}$ It has been reported that LFCSBP is related to the supraspinal cardiovascular centre and peripheral sympathetic outflow ${ }^{9}$ and that its amplitude reflects sympathetic vasomotor activity. ${ }^{10}$ Therefore, LFCSBP indicates sympathetic activity and reflects peripheral sympathetic vasomotor activity. Increase of LFCSBP suggests that peripheral sympathetic vasomotor activity increases due to low epidural anaesthesia. It has been reported that the sympathetic activity in the anaesthetized area was suppressed by lumbar epidural anaesthesia. ${ }^{4}$ Therefore, in this study, we assumed that the peripheral sympathetic vasomotor activity in the upper unanaesthetized area was compensatorily activated. It has been reported that baroreflex sensitivities were increased during both activation of the reflex by phenylephrine and deactivation of the reflex by nitroglycerine during lumbar epidural anaesthesia (mean upper level $T_{10}$ ). ${ }^{13}$ 


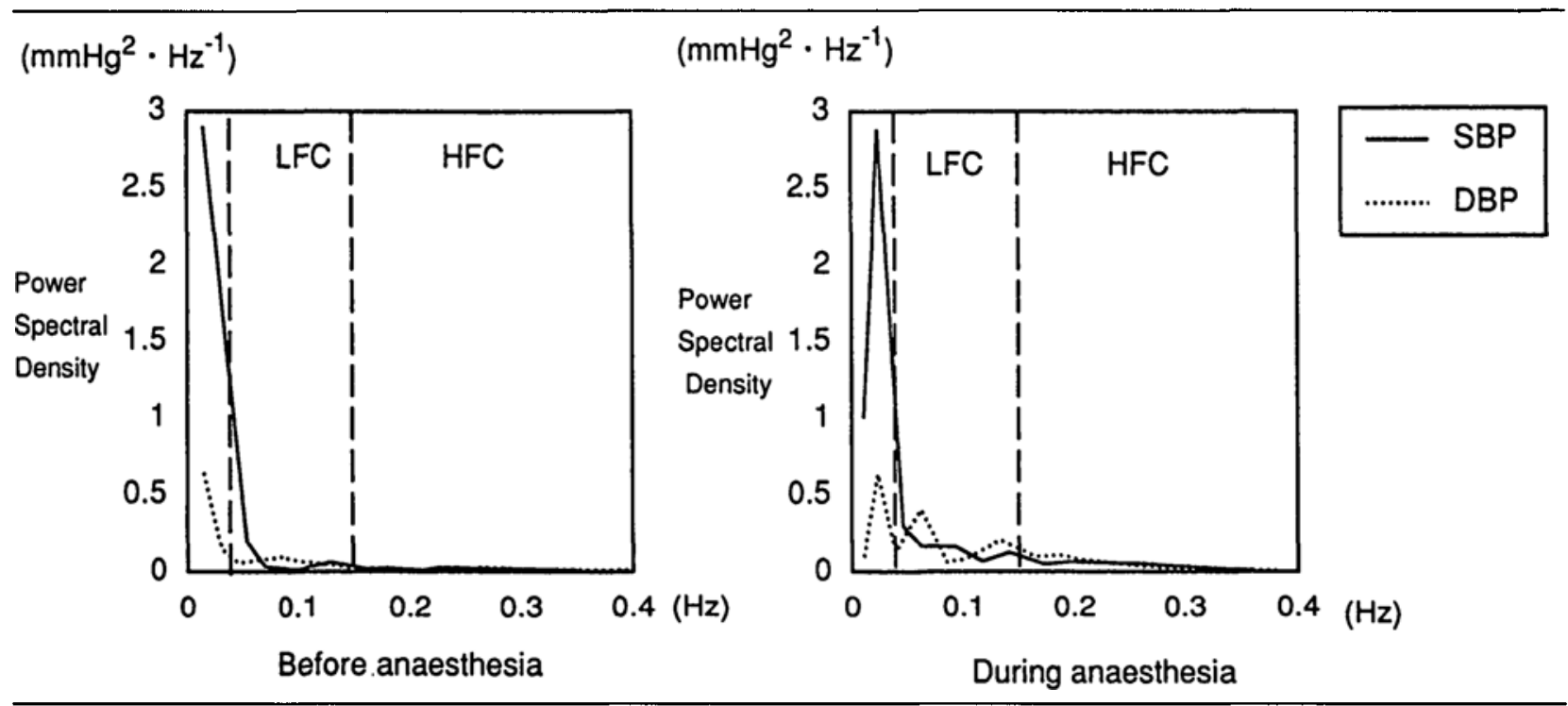

FIGURE 3 . Power spectrum of blood pressure variability before and during anaesthesia in low epidural anaesthesia group. Low frequency component of systolic blood pressure variability (LFCSBP) increased during epidural anaesthesia.

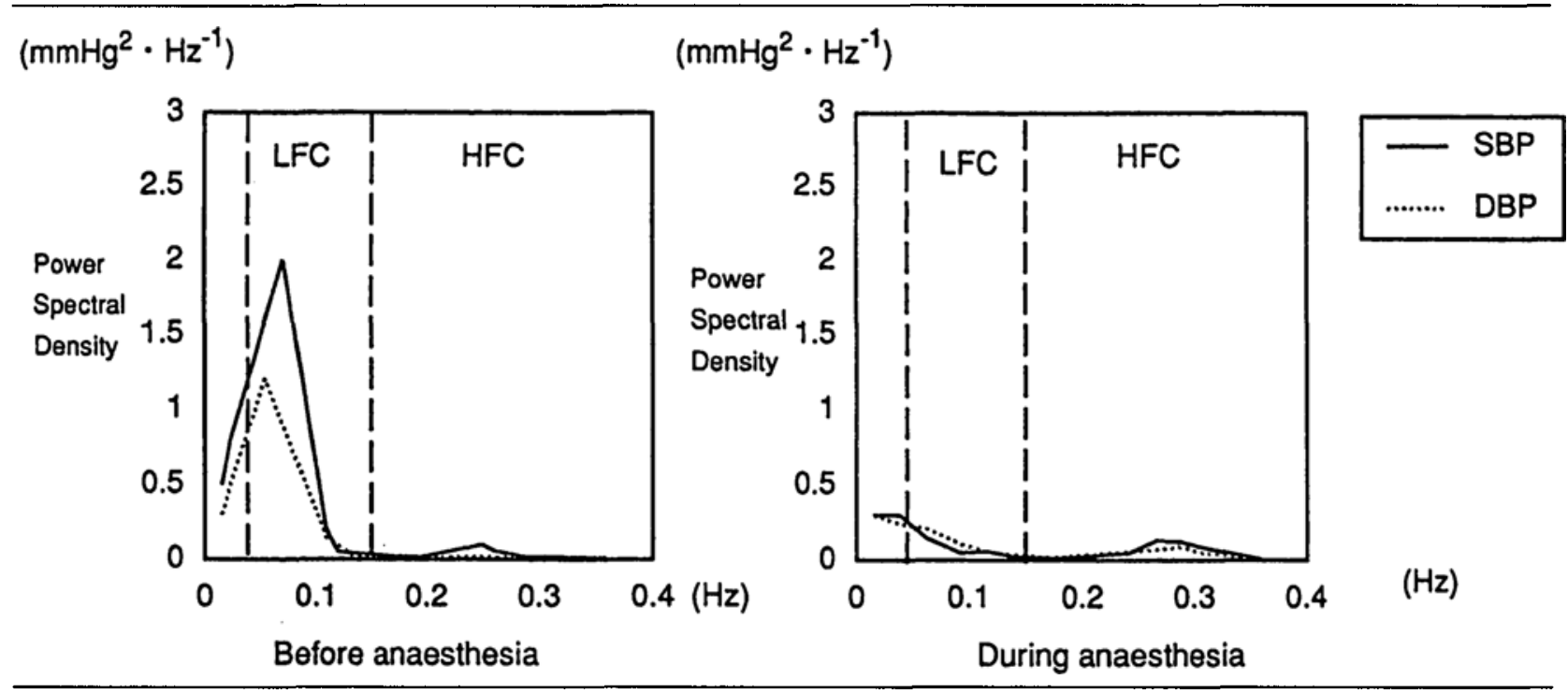

FIGURE 4 Power spectrum of blood pressure variability before and during anaesthesia in high epidural anaesthesia group. Low frequency component of systolic and diastolic blood pressure variabilities (LFCSBP and LFCDBP) decreased during epidural anaesthesia.

Increment of LFCsBP probably relates to the activation of baroreflex sensitivity.

Decrement of LFCSBP and LFCDBP suggests that peripheral sympathetic vasomotor activity decreases due to high epidural anaesthesia. This is because the level of sympathetic block in the spinal cord is wider and the release of hormones from the adrenal gland that is innervated by $T_{6}-L_{2}$ in the spinal cord is blocked by epidural anaesthesia. It suggests that lumbar epidural anaesthesia mainly changes peripheral sympathetic vasomotor activity in the autonomic nervous system.
Earlier studies with autonomic blocking drugs and postural change suggested that LFCRR reflects the Mayer waves and is mediated by both sympathetic and parasympathetic activity and that HFCRR corresponds to respiratory sinus arrhythmia and reflects only parasympathetic activities. The LFCRR/HFCRR ratio was reduced by acute and chronic $\beta$-adrenergic receptor blockade. ${ }^{5}$ Therefore, the LFCRR/HFCRR ratio is an index of sympathetic activity.

There were no changes in heart rate variability after epidural anaesthesia. Though the reason is not clear, we 
assume that, even if sympathetic activity was decreased by epidural anaesthesia, the LFCRR did not always decrease because it was mediated by both sympathetic and parasympathetic activities. Therefore, we assume that lumbar epidural anaesthesia did not affect LFCRR, nor did it affect parasympathetic activity, because it did not change HFCRR.

However, in the low epidural anaesthesia group, the LFCRR/HFCRR ratio tended to increase while in the high epidural anaesthesia group, the ratio tended to decrease. There were no significant changes in the LFCRR/HFCRR ratio after epidural anaesthesia. These results suggest that sympathetic activity tended to increase in the low epidural anaesthesia group, and decrease in the high epidural anaesthesia group.

There were no differences in blood pressure and heart rate between the low and the high epidural anaesthesia groups. The infused volume of Ringer's lactate solution induced was higher in the high epidural anaesthesia group than in the epidural anaesthesia group. In order to evaluate preload accurately, it would be necessary to measure the central venous pressure and/or pulmonary artery occlusion pressure.

Spinal anaesthesia has a depressant effect on adrenergic tone dependent on the dermatome block level, and produces a marked decrease in both plasma norepinephrine and epinephrine concentrations when the level was $\mathrm{T}_{6}$ or higher. ${ }^{14}$ Sympathetic activity was decreased and parasympathetic activity was increased by spinal anaesthesia using FFT (mean upper dermal level $\mathrm{T}_{4}$ ). ${ }^{15}$ It has been reported that sympathetic block produced by spinal anaesthesia extended two to six dermal segments higher than the sensory loss. ${ }^{16}$ Therefore, when the mean upper dermatome level is $T_{4}$ in spinal anaesthesia, cardiac preganglionic sympathetic accelerator fibres $\left(T_{1-4}\right)$ are blocked. In this study it is not clear why there were no changes in the spectral components of heart rate and variability during epidural anaesthesia. We assume that cardiac preganglionic sympathetic accelerator fibres are not completely blocked by epidural anaesthesia because the mean upper dermatome level was either $T_{5.1}$ or $T_{10.7}$ and there was no reduction in heart rate in either groups. It has been reported that the plasma concentration of norepinephrine decreased when the level of sensory analgesia was $\mathrm{C}_{8}$ in lumbar epidural anaesthesia. ${ }^{17} \mathrm{We}$ assume that there would have been changes in heart rate variability if the epidural anaesthesia had blocked cardiac preganglionic sympathetic accelerator fibres completely.

We conclude that peripheral sympathetic vasomotor activity was activated in low lumbar epidural anaesthesia and peripheral sympathetic vasomotor activity was suppressed in high lumbar epidural anaesthesia.

\section{References}

1 Malmqvist LA, Tryggvason B, Bengtsson $M$. Sympathetic blockade during extradural analgesia with mepivacaine or bupivacaine. Acta Anaesthesiol Scand 1989; 33: 444-9.

2 Lundin $S$, Wallin BG, Elam $M$. Intraneural recording of muscle sympathetic activity during epidural anesthesia in humans. Anesth Analg 1989; 69: 788-93.

3 Valley MA, Bourke DL, Hamill MP, Raja SN. Time course of sympathetic blockade during epidural anesthesia: laser doppler flowmetry studies of regional skin perfusion. Anesth Analg 1993; 76: 289-94.

4 Baron JF, Payen D, Coriat P, Edouard A, Viars $P$. Forearm vascular tone and reactivity during lumbar epidural anesthesia. Anesth Analg 1988; 67: 1065-70.

5 Pagani M, Lombardi F, Guzzetti S, et al. Power spectral analysis of heart rate and arterial pressure variabilities as a marker of sympatho-vagal interaction in man and conscious dog. Circ Res 1988; 59: 178-93.

6 Akeselrod S, Gordon D, Ubel FA, Shannon DC, Berger $A C$, Cohen RJ. Power spectum analysis of heart rate fluctuation: a quantitative probe of beat-to-beat cardiovascular control. Science 1981; 213: 220-2.

7 Iwaski $M$. A study of the role of the autonomic nervous function in systolic blood pressure fluctuation using tonometry. The Autonomic Nervous System 1991; 29: 49-57.

8 Japundzic N, Grichois ML, Zitoun P, Laude D, Elghozi $J L$. Spectral analysis of blood pressure and heart rate in conscious rats: effects of autonomic blockers. J Auton Nerv Syst 1990; 30: 91-100.

9 Inoue $K$, Miyake S, Kumashiro M, Ogata H, Ueta $T$, Akatsu $T$. Power spectral analysis of blood pressure variability in traumatic quadriplegic humans. Am J Physiol 1991; 260: H842-7.

10 Rimoldi $O$, Pierini $S$, Ferrari $A$, Cerutti $S$, Pagani $M$, Malliani $A$. Analysis of short term oscillations of $\mathrm{R}-\mathrm{R}$ and arterial pressure in conscious dogs. Am J Physiol 1990; 258: H967-76.

11 Kemmotsu O, Ueda $M$, Otsuka $H$, et al. Blood pressure measurement by arterial tonometry in controlled hypotension. Anesth Analg 1991; 73: 54-8.

12 DeBoer RW, Karemaker JM, Strackee J. Hemodynamic fluctuations and baroreflex sensitivity in humans: a beat-tobeat model. Am J Physiol 1987; 253: H680-9.

13 Baron JF, Decaux-Jacolot A, Edouard A, Berdeaux A, Samii $K$. Influence of venous return on baroreflex control of heart rate during lumbar epidural anesthesia in humans. Anesthesiology 1986; 64: 188-93.

14 Pflug $A E$, Halter $J B$. Effect of spinal anesethesia on adrenergic tone and the neuroendocrine responses to surgical stress in humans. Anesthesiology 1981; 55: 120-6.

15 Kawamoto M, Tanaka N, Takasaki M. Power spectral analysis of heart rate variability after spinal anaesthesia. $\mathrm{Br}$ J Anaesth 1993; 71: 523-7. 
16 Chamberlain DP, Chamberlain BDL. Changes in the skin temperature of the trunk and their relationship to sympathetic blockade during spinal anesthesia. Anesthesiology 1986; 65: 139-43.

17 Stevens $R A$, Artuso JD, Kao TC, Bray JG, Spitzer $L$, Louwsma $D L$. Changes in human plasma catecholamine concentrations during epidural anesthesia depend on the level of block. Anesthesiology 1991; 74: 1029-34. 